\title{
Exosome-shuttled miRNAs contribute to the modulation of the neuroinflammatory microglia phenotype by mesenchymal stem cells. Implication for amyotrophic lateral sclerosis
}

Debora Giunti ( $\sim$ dgiunti@neurologia.unige.it)

University of Genoa https://orcid.org/0000-0002-0673-2646

Chiara Marini

Universita degli Studi di Genova

Benedetta Parodi

Universita degli Studi di Genova

Cesare Usai

Consiglio Nazionale delle Ricerche

Marco Milanese

University of Genoa

Giambattista Bonanno

Universita degli Studi di Genova

Nicole Kerlero de Rosbo

Universita degli Studi di Genova

Antonio Uccelli

Universita degli Studi di Genova

\section{Research}

Keywords: Neuroinflammation, exosomes, microRNA, mesenchymal stem cell, microglia, amyotrophic lateral sclerosis

Posted Date: November 28th, 2019

DOI: https://doi.org/10.21203/rs.2.17858/v1

License: (1) This work is licensed under a Creative Commons Attribution 4.0 International License. Read Full License 


\section{Abstract}

Background Mesenchymal stromal/stem cells (MSCs) are characterized by neuroprotective, immunomodulatory, and neuroregenerative properties, which support their therapeutic potential for neurodegenerative diseases driven by microglia-associated inflammation, such as amyotrophic lateral sclerosis (ALS). One mode of action through which MSCs exert their immunomodulatory effects is the release of extracellular vesicles, including exosomes, that carry proteins, mRNAs, and microRNAs (miRNAs), which, once transferred, modify the function of target cells. We have investigated the role of miRNAs present in exosomes derived from IFN- $\gamma$-primed mouse MSCs in the modulation of microglia activation, and analysed their effect on target genes and signaling pathways.

Methods We compared miRNA expression in IFN-y-primed vs unprimed mouse MSCs by microarray and measured the levels of relevant miRNAs in their respective exosomes through RT-PCR. To assess the effect of dysregulated MSC-derived miRNAs, we transfected lipopolysaccharide-activated N9 microglial line cells and primary microglia from late-symptomatic SOD1G93A ALS mice with their specific mimics and analysed the mRNA expression of pro/anti-inflammatory genes in the cells. We used mirWalk and Panther and KEGG Pathway databases to predict target genes of specific miRNAs and possible pathways they regulate. Data were compared using Student's t-test.

Results We identified nine miRNAs that were significantly dysregulated in IFN-y-primed MSCs, but present at different levels in their derived exosomes. Transfection with three of the four miRNAs significantly upregulated in IFN- $\gamma$-primed MSC-derived exosomes, namely miR-467f, miR-466q and miR-466m-5p, could modulate the pro-inflammatory phenotype of N9 microglia by downregulating Tnf and/or Il1b expression, and/or upregulating $\mathrm{Cx} 3 \mathrm{cr} 1$ expression. We obtained similar results in primary microglia from SOD1G93A mice transfected with miR-467f and miR-466q. Further analysis of the mode of action of miR$467 \mathrm{f}$ and miR-466q indicated that they dampen the pro-inflammatory phenotype of microglia by modulating the p38 MAPK signaling pathway via inhibition of the expression of their target genes, Map3k8 and Mk2.

Conclusion These results suggest that exosome-mediated transfer of functional miRNAs could be one mode of action through which MSCs exert their therapeutic effect in ALS by downregulating neuroinflammatory microglia, and identify miR-467f and miR-466q as immunomodulatory miRNAs involved in this process.

\section{Background}

Mesenchymal stromal/stem cells (MSCs) are multipotent adult stromal cells with self-renewing potential characterized by their ability to differentiate into cells of the mesodermal lineage. The evidence that bone marrow-derived MSCs are able to inhibit T-cell proliferation in vitro [1] set the basis for the demonstration of broad immunomodulatory activities of MSCs on different cells of both innate and adaptive immunity [2]. Numerous in-vitro studies have shown that a large part of the effects of MSCs on immune cells can 
be accounted for by paracrine mechanisms, in particular through soluble factors released constitutively $[3,4]$ or through crosstalk with target cells. In this context, MSCs have been shown to affect the proinflammatory profile of microglia, the resident immune cells in the brain. Thus, transforming growth factor beta secreted by MSCs skewed the phenotype of lipopolysaccharide (LPS)-stimulated microglia from classically activated M1-like to protective M2-like, by inhibiting the nuclear factor kappa-light-chainenhancer of activated B cells (NF-KB) pathway, thereby reducing pro-inflammatory cytokine expression [5]; similarly, MSCs inhibited the activation of NF-KB and mitogen-activated protein kinase (MAPK) pathways in LPS-stimulated BV2 microglial cells and, therefore, their polarization to the pro-inflammatory phenotype through the secretion of tumor necrosis factor-a-induced gene/protein 6 (TSG-6) [6]. In other studies, colony-stimulating factor- 1 was found to be one MSC secretome molecule responsible for the anti-inflammatory effect of MSCs on LPS-activated microglia [7], and MSCs were shown to exert a "calming" effect on pro-inflammatory microglia through the release of CX3CL1 that upregulates the CX3CR1/CX3CL1 axis involved in the control of microglia activation [8]. It should be noted that MSCderived microvesicles were also recently demonstrated to be modulators of LPS-induced microglia activation [9].

Such studies have led to administration of MSCs being considered as a possible alternative therapeutic approach for controlling neurological diseases associated with neuroinflammation [10], including multiple sclerosis [11, 12] and amyotrophic lateral sclerosis (ALS) [13-15]. In vivo studies in our laboratory [13] have shown that intravenous administration of MSCs in mice that express the human $\mathrm{Cu}, \mathrm{Zn}$ superoxide dismutase-1 carrying the $\mathrm{G} 93 \mathrm{~A}$ point mutation $\left(\mathrm{SOD} 1^{\mathrm{G} 93 \mathrm{~A}}\right)$, a widely used experimental model for ALS, during the symptomatic stage of disease, significantly improve the clinical outcome and pathological scores [13]. The beneficial effect is related to the decrease of oxidative stress and the inhibition of glutamate-mediated excitotoxicity, but also to a reduction in astrocyte and microglia proliferation and related neuroinflammation [13]. Similarly, ALS mice treated with human MSCs through transplantation into the spinal cord [16] or multiple systemic administration [17] showed decreased microglia and astrocyte activation and improved motor performance.

In addition to soluble factors, extracellular vesicles are a key instrument in cell-cell communication [18]. Among the many subtypes of extracellular vesicles, exosomes have emerged as physiologically relevant and powerful components of the MSC secretome $[19,20]$. Exosomes are small vesicles with a diameter of 40-120 nm, with a specific molecular composition that depends on the cell of origin and the cellular context [21]. Together with specific proteins, lipids, and mRNAs, the exosome cargo is rich in various microRNAs (miRNAs), which are small sequences of RNA that, when transferred to the cytoplasm of target cells, govern various processes, preventing protein translation. Indeed, they modulate gene expression at post-transcriptional level via mRNA degradation, translational repression, or both, in target cells [22].

The aim of this study was to assess, in vitro, if the immunomodulatory effect of MSCs on neuroinflammation could be attributed, at least in part, to their release of exosomes that shuttle specific miRNAs able to downregulate the pro-inflammatory phenotype of activated microglia, and to define the 
mode of action of these "immunomodulatory" miRNA(s) through identification and validation of their target genes involved in the inflammatory pathway.

\section{Methods}

\section{Microarray analysis to compare miRNA expression in MSCs primed or not with IFN- $\gamma$}

Bone marrow-derived MSCs were isolated from 6- to 8-week-old C57BL/6J mice (Harlan Laboratories), expanded, and characterized as described previously [11]. The experiments were approved by the Animal Ethics Committee of Ospedale Policlinico San Martino and by the Italian Ministry of Health (Approval Number: 384; authorization No. 230/2016-PR). All applicable international, national, and/or institutional guidelines for the care and use of animals were followed (Decreto Legislativo 4 marzo 2014, n. 26, legislative transposition of Directive 2010/63/EU of the European Parliament and of the Council of 22 September 2010 on the protection of animals used for scientific purposes).

Expanded MSCs were stimulated with $10 \mathrm{ng} / \mathrm{ml} \mathrm{IFN-y} \mathrm{for} 24$ hours at $37^{\circ} \mathrm{C}$, as described previously, in order to increase their immunomodulatory features [23]. The whole mRNA fraction was isolated from three different batches of MSCs unprimed or primed with IFN-y at passage 14/15, which were shown to be immunosuppressive as demonstrated by their ability to inhibit T-cell proliferation [23]. Microarray analysis was performed and analysed by LC Science (Houston, TX) according to the MIAME guidelines [24], using Student's t-test to compare data from unprimed and IFN-y-primed samples for each batch separately, as well as for pooled batches.

\section{Isolation and characterization of MSC-derived exosomes}

In order to increase their production of exosomes, expanded IFN-y-primed and unprimed MSCs were stimulated for 20 minutes with $1 \mathrm{mM}$ ATP (Sigma-Aldrich) at $37^{\circ} \mathrm{C}$ [25]. The resulting supernatant was centrifuged at $2,000 \times \mathrm{g}$ at $4^{\circ} \mathrm{C}$ for 20 minutes to eliminate cells and debris, and incubated overnight at $4^{\circ}$ $\mathrm{C}$ with 0.5 volume of Total Exosome Isolation Kit (Invitrogen). After the incubation, the sample was centrifuged at $10,000 \times \mathrm{g}$ at $4^{\circ} \mathrm{C}$ for 1 hour and the pellet containing the exosomes was resuspended accordingly to the experimental needs.

For characterization by western blot analysis, $15 \mu \mathrm{g}$ of exosome proteins were loaded on a precast polyacrylamide gel (from $4 \%$ to $12 \%$ gradient, Life Technologies), using the Bolt $\circledast$ Mini Gel Tank (Life Technologies) system. Protein were then transferred on a nitrocellulose membrane (BioRad) using XCell $\mathrm{II}^{\mathrm{TM}}$ Blot Module (Life Technologies). After blocking in 5\% BSA in PBS/Tween 20 for 1 hour, the membrane was incubated overnight at $4^{\circ} \mathrm{C}$ with primary rabbit anti-ALIX (1:1000, Merck Millipore, Milan, Italy) and anti-CD9 (1:1000, BD Pharmigen) antibodies in 2\% BSA in PBS/Tween 20. Membranes were incubated with secondary goat anti-rabbit IgG antibody conjugated with horseradish peroxidase (1:5000, Merck 
Millipore) in 2\% BSA in PBS/Tween 20 for 1 hour. Membranes were developed using the ECL Plus kit (Thermo Fisher Scientific).

For characterization by electron microscopy, exosomes collected from $7 \times 10^{6} \mathrm{MSC}$ were fixed in a volume of $50-100 \mu \mathrm{l}$ of $2 \%$ paraformaldehyde, according to a published protocol [26]. $5 \mu$ l of resuspended pellet was allowed to adhere to electron microscopy grids (Formvar-Carbon) for 20 minutes at $42^{\circ} \mathrm{C}$. Subsequently, the grids were washed 2 times with $100 \mu$ PBS for 3 minutes, once with $1 \%$ glutaraldehyde for 5 minutes, and finally seven times with $100 \mu \mathrm{l}$ of distilled water for 2 minutes each. For contrast phase microscopy, the samples were transferred to $50 \mu \mathrm{l} \%$ uranyl acetate (UA) solution for 5 minutes and then to $50 \mu \mathrm{l}$ of methylcellulose (MC) and UA ( $9 \mathrm{ml} \mathrm{MC}+1 \mathrm{ml} \mathrm{UA} \mathrm{4 \% )} \mathrm{for} 10$ minutes in ice. The sections were dried on a filter paper and then in the air, visualized using a FEI CM10 microscope, and acquired via a Leo912ab camera.

\section{Culture and activation of $\mathrm{N} 9$ microglia line cells}

The murine microglial cell line N9 (Neuro-Zone srl, Italy) was plated in $75 \mathrm{~cm}^{2}$ cell culture flasks at a concentration of $5-6 \times 10^{5}$ cells in $15 \mathrm{ml} \mathrm{RPMI}$ (Sigma-Aldrich) containing $10 \%$ fetal bovine serum (FBS) (Lonza), $100 \mathrm{U} / \mathrm{ml}$ penicillin, and $100 \mu \mathrm{g} / \mathrm{ml}$ streptomycin, and maintained at $37^{\circ} \mathrm{C}$ and $5 \% \mathrm{CO}^{2}$ in incubator. The cells were activated by exposure to $1 \mu \mathrm{g} / \mathrm{ml}$ LPS (Sigma-Aldrich) for 30 minutes for the immunofluorescence experiments and for 24 hours for the RT-PCR experiments, as indicated in the legends to the relevant figures.

\section{Mice}

B6SJL-TgN SOD1/G93A1Gur mice expressing a high copy number of mutant human SOD1 with a Gly to Ala substitution at position 93 (referred to thereafter as SOD1 ${ }^{\text {G93A }}$ mice) and B6SJL-TgN (SOD1)2Gur mice expressing wild-type human SOD1 [27] (referred to thereafter as wtSOD1 mice) were originally obtained from Jackson Laboratories (Bar Harbor, ME, USA) and bred at the animal facility of the Pharmacology and Toxicology Unit, Department of Pharmacy at the University of Genoa, Genoa, where they were kept until experiments were carried out.

All mice were housed in pathogen-free conditions with food and water ad libitum. All applicable international, national, and/or institutional guidelines for the care and use of animals were followed (Decreto Legislativo 4 marzo 2014, n. 26, legislative transposition of Directive 2010/63/EU of the European Parliament and of the Council of 22 September 2010 on the protection of animals used for scientific purposes). The research protocol was approved by the Ethical Committee for Animal Experimentation of the University of Genoa, Italy, and the Italian Ministry of Health (Project No. 75f11.3, Authorization No.482/2017-PR). 
The onset of overt clinical symptoms in our SOD $1^{\text {G93A }}$ mouse colony occurs at approximately day 90 [28]. Animals were sacrificed at the end stage of disease, established according to an homogeneous motor impairment severity score (extension reflex and gait impairment score: 4.5 units, at around 135 days of age) as previously described [13] and characterized by an overactivation of microglia [29].

\section{Isolation of adult primary microglia}

Primary microglia were isolated from the brain of late stage SOD $1^{\mathrm{G} 93 \mathrm{~A}}$ and age-matched wtSOD 1 mice, following the protocol of Cardona et al. [30], with minor modifications. Each brain was chopped in a Petri dish and transferred into a $15 \mathrm{ml}$ Falcon tube; after centrifugation, the pellet was resuspended in $2 \mathrm{ml}$ of activated papain solution (Roche) containing 0.5\% $14.3 \mathrm{mM} \beta$-mercaptoethanol (final concentration 72 $\mu \mathrm{M})$ for 30 minutes at $37^{\circ} \mathrm{C}$ in a water bath, resuspending every 10 minutes. $500 \mu$ l of RPMI containing $100 \mu \mathrm{M}$ leupeptin (R\&D Systems) were added to the suspension, which was mixed thoroughly for 2 minutes. $8 \mathrm{ml}$ prewarmed Dnase solution (Sigma) (composed of RPMl containing Ca2+ and Mg2+, 25 $\mathrm{mM} \mathrm{HEPES}$ and $30 \mu \mathrm{g} / \mathrm{mL}$ Dnase) were added to the samples and incubated for 10 minutes at $37^{\circ} \mathrm{C}$. Suspensions were filtered on a 100-250 $\mu \mathrm{m}$ filter and centrifuged at $450 \mathrm{xg}$ at $4^{\circ} \mathrm{C}$ for 5 minutes. Supernatants were aspirated and the pellets were resuspended in $7.2 \mathrm{ml}$ of wash solution (RPMI and $1 \mathrm{M}$ HEPES); $1.2 \mathrm{ml}$ of FBS was mixed with the cell suspension, followed by $3.6 \mathrm{ml}$ of $100 \%$ Percoll (SigmaAldrich). Finally, $1 \mathrm{ml}$ of $10 \%$ FBS in RPMI was layered over the cell suspension and samples were centrifuged at $800 \mathrm{xg}$ at $4^{\circ} \mathrm{C}$ for 15 minutes without brake. Pellets were resuspended in $1 \mathrm{ml}$ RPMI with $10 \%$ of FBS and cells were counted. An average of $5-6 \times 10^{6}$ cells was obtained per single brain and the primary microglia were further purified on CD11b (Microglia) MicroBeads (Miltenyi Biotec) according to the manufacturer's instructions. It is notoriously difficult to obtain pure mouse microglia from adult brain and we reached an average yield of $3-5 \times 10^{5}$ microglia per single brain with a final purity of $85-90 \%$.

\section{Microglia exposure to IFN-y primed MSC-derived exosomes}

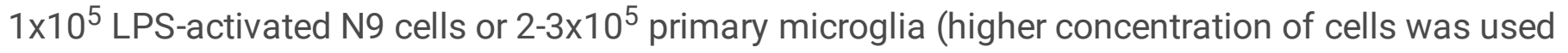
because of the low survival of primary microglia in culture) resuspended in $1 \mathrm{ml}$ RPMI were plated per well in a 24-well plate in presence or absence of IFN-y primed MSC-derived exosomes (exos IFN- - -MSC $^{\text {. }}$. The quantity of exosomes added to the cultures was equivalent to that produced by MSCs at a microglia:MSC ratio of $1: 3$. After 24 hours at $37^{\circ} \mathrm{C}$ and $5 \% \mathrm{CO}^{2}$, cells were processed for RNA extraction.

\section{RNA isolation and Real Time quantification}


Total RNA was isolated from N9 cells and primary microglia using QIAzol Lysis Reagent (Qiagen) according to the manufacturer's instructions. First strand cDNA was synthesized from $1 \mu \mathrm{g}$ of total RNA from N9 cells or $500 \mathrm{ng}$ of total RNA from primary microglia using Transcriptor First Strand cDNA synthesis kit (Roche Diagnostics, Germany), in a final volume of $20 \mu$.

Real Time polymerase chain reaction (RT-PCR) was performed in LightCycler 480 (Roche) in duplicate in a final volume of $20 \mu \mathrm{l}$ containing $50 \mathrm{ng}$ cDNA, $1 \mu$ of each primer pair $20 \mathrm{mM}$ (TIB Mol Biol), $10 \mu \mathrm{l}$ of FastStart Essential DNA Green Master Mix (Roche). The amplification of the 3-phosphate dehydrogenase glyceraldehyde (GAPDH) gene as housekeeping gene was adopted to normalize expression data. Primer sequences used: tumor necrosis factor (Tnf) forward (5'-TCTTCTCATTCCTGCTTGTGG-3') and reverse (5'GGTCTGGGCCATAGAACTGA-3'); interleukin 1b (Il1b) forward (5'-AGTTGACGGACCCCAAAAG-3') and reverse (5'-TTTGAAGCTGGATGCTCTCAT-3'); IL-18 (II18) forward (5'- CAAACCTTCCAAATCACTTCCT-3') and reverse (5'- TCCTTGAAGTTGACGCAAGA-3'); CX3cr1 forward (5'-AAGTTCCCTTCCCATCTGCT-3') and reverse (5'- CAAAATTCTCTAGATCCAGTTCAGG-3'); nuclear receptor subfamily 4 group A (Nr4a2) forward (5'-TCAGAGCCCACGTCGATT-3') and reverse (5'-TAGTCAGGGTTTGCCTGGAA-3'); cluster of differentiation 206 (Cd206) forward (5'-CCACAGCATTGAGGAGTTTG-3') and reverse (5'-ACAGCTCATCATTTGGCTCA-3'); mitogen-activated protein kinase (MAPK) kinase kinase 8 (Map3k8) forward (5'TTCCAGTGCTCATGTACTCCA-3') and reverse (5'-GGACTGCTGAACTCTGTTTGC-3'); MAPK-activated protein kinase 2 (Mk2) forward (5'-AGTGCAGCTCCACCTCTCTG-3') and reverse (5'-

CAGCAAAAATTCGCCCTAAA-3'); GAPDH forward (5'-ATGGTGAAGGTCGGTGTGA-3') and reverse (5'AATCTCCACTTTGCCACTGC-3').

For miRNA amplification, RNA was isolated from exosomes using miRNeasy Mini Kit (Qiagen) according to the manifacturer's instructions. The cDNA was obtained from $200 \mathrm{ng}$ of total mRNA using miScript II RT Kit (Qiagen). miRNA amplification was performed in LightCycler 480 (Roche) in duplicate in a final volume of $25 \mu$ l containing $2.5 \mathrm{ng}$ cDNA (miScript SYBR green PCR kit, Qiagen). Amplification of Scarna17 (Qiagen) miRNA was used to normalize expression data. Primer sequences used: miR-467f 5'ATATACACACACACACCTACA-3'; miR-466q 5'-GTGCACACACACACATACGT-3'; miR-466m-5p 5'TGTGTGCATGTGCATGTGTGTAT-3'; miR-466i-3p 5'-ATACACACACACATACACACTA-3'; miR-466i-5p 5'TGTGTGTGTGTGTGTGTGTG-3'; miR-467g 5'-TATACATACACACACATATAT-3'; miR-3082-5p 5'GACAGAGTGTGTGTGTCTGTGT-3'; miR-5126 5'-GCGGGCGGGGCCGGGGGCGGGG-3'; miR-669c-3p 5'TACACACACACACACAAGTAAA-3'.

\section{N9 and primary microglia transfection}

$1 \times 10^{5}$ cells were plated in 24-well plates in $500 \mu \mathrm{RPMI}$ and transfected using the HiPerFect ${ }^{\circledR}$ Transfection Reagent (Qiagen), according to the manufacturer's instructions, with mimics specific for miRNA (miRNA Mimic miRNA, Qiagen) and with MISSION miRNA Mimic Negative Control (SigmaAldrich), a synthetic miRNA which does not recognize any mRNA target in cells (Cneg), and with iBONi 
siRNA positive control-P4M (Riboxx), which inhibits the translation of GAPDH in cells, as indicator of efficient transfection (Cpos). The sequence of mimics used are: miR-467f 5'-

AUAUACACACACACACCUACA-3'; miR-466q 5'-GUGCACACACACACAUACGU-3'; miR-466m-5p 5'-

UGUGUGCAUGUGCAUGUGUGUAU-3'; miR-466i-3p 5'-AUACACACACACAUACACACUA-3'; miR-466i-5p 5'UGUGUGUGUGUGUGUGUGUG-3'; miR-467g 5'-UAUACAUACACACACAUAUAU-3'; miR-3082-5p 5'-

GACAGAGUGUGUGUGUCUGUGU-3'; miR-5126 5'-GCGGGCGGGGCCGGGGGCGGGG-3'; miR-669c-3p 5'UACACACACACACACAAGUAAA-3'.

\section{Bioinformatics analysis of miRNA targets}

Online software miRWalk 2.0 was consulted to predict specific target genes of relevant miRNAs in common among different databases, such as MicroT4, miRanda and Targetscan. Pathways which selected miRNAs might modulate, were predicted in-silico using Kyoto encyclopedia of genes and genomes (KEGG) Pathway database which predicts possible pathways based on the involvement of the miRNA itself in regulating the pathway, and Panther Classification System, which predicts the pathways in which components coded for by the predicted target genes of the miRNA are involved.

\section{Quantification of phospho-p38 MAPK by immunofluorescence}

$1 \times 10^{5} \mathrm{~N} 9$ cells were seeded in glass coverslips in a 24-well plate with $500 \mu \mathrm{l} \mathrm{RPMI}+10 \% \mathrm{FBS}$ and incubated at $37^{\circ} \mathrm{C}$ and $5 \% \mathrm{CO}^{2}$ for 1 hour. They were transfected for 24 hours with each miRNA individually or as a mix, and with Cneg or Cpos, and stimulated with $1 \mu \mathrm{g} / \mathrm{ml}$ LPS for 30 minutes. Then, cells were fixed with $350 \mu \mathrm{l} \mathrm{PFA} 4 \%$ for 20 minutes at $4^{\circ} \mathrm{C}$. After three washes with $500 \mu \mathrm{l} \mathrm{PBS}$, the N9 cellular membrane was permeabilized with $200 \mu \mathrm{l}$ PBS $+0.25 \%$ Triton X-100 for 10 minutes at room temperature. After three washes with $350 \mu \mathrm{l}$ PBS, $250 \mu \mathrm{l}$ PBS containing 1\% BSA (PBS/BSA) were added to the wells for 30 minutes at room temperature, for blocking non-specific bonds. After removing the medium, primary monoclonal rabbit anti-phospho-p38 MAPK (Thr180/Tyr182) antibody (clone D3F9) XP® (Cell Signaling Technology; 1:2000) and mouse anti-GAPDH antibody (Sigma-Aldrich; 1:1000) in 200 $\mu \mathrm{I}$ PBS/BSA were added per well and the cells were incubated at room temperature for 1 hour. After three washes with $350 \mu$ PBS, N9 cells were incubated with cross-absorbed secondary antibodies, Alexa Fluor 594-conjugated goat anti-rabbit IgG $(\mathrm{H}+\mathrm{L})$ (Invitrogen; 1:1000) and Alexa Fluor 488-conjugated goat antimouse IgG (H+L) (Invitrogen; 1:3000) in $100 \mu \mathrm{l} \mathrm{PBS/BSA} \mathrm{for} 45$ minutes at room temperature in the dark. After three washes with $350 \mu \mathrm{l}$ PBS, cells were exposed to DAPI (4',6-Diamidino-2-Phenylindole, Dihydrochloride) (Invitrogen) for 2 minutes and washed twice with $100 \mu$ PBS. Coverslips were fixed with Fluoromount $^{\mathrm{TM}}$ Aqueous Mounting Medium (Sigma-Aldrich). Fluorescence image acquisition was performed by a Leica TCS SP5 laser-scanning confocal microscope, through a plan-apochromatic oil immersion objective $63 \mathrm{X} / 1.4 \mathrm{NA}$. The quantitative estimation of co-localized proteins was performed by calculating the 'co-localization coefficients'[31]. 
According to Costes et al. [32], the correlation between the green and red channels was evaluated with a significance level $>95 \%$. Costes' approach was carried out by macro routines (WCIF Colocalization Plugins, Wright Cell Imaging Facility, Toronto Western Research Institute, Canada) integrated as plugins in the ImageJ 1.52q software (Wayne Rasband, NIH, USA).

\section{Statistical analysis}

The results are presented as mean \pm standard error (SEM). Statistical analysis was performed on independent experiments using Student's t-test through the Prism 5 program (GraphPad Software, La Jolla, CA). In all analyses, $P<0.05$ is considered statistically significant.

\section{Results}

\section{Microarray analysis showed a significant dysregulation of nine miRNAs in IFN-ץ-primed MSCs}

As already known from the literature, the immunomodulatory effects of MSCs are promoted through environmental factors, in particular inflammatory cytokines that "prime" MSCs to become immunosuppressive through the concerted action of nitric oxide [33] and many other factors [34].

IFN- $y$ has been described to significantly affect human and mouse MSC function [35, 36]; in particular, high concentration of IFN- $\gamma$ induces the phosphorylation of signal transducer and activator of transcription 1 and 3 and inhibits the mammalian target of rapamycin activity which favors nuclear translocation of signal transducer and activator of transcription 1, resulting in an increase in MSC immunomodulatory function [23].

To verify if the immunomodulatory phenotype of MSCs could be associated with changes in miRNA expression, we used three different batches of MSCs to compare the expression of miRNAs by MSCs primed with IFN- $y$ with that of unprimed MSCs. Microarray analysis identified nine miRNAs, miR-467f, miR-466q, miR-466m-5p, miR-466i-3p, miR-466i-5p, miR-467g, miR-3082-5p, miR-5126, and miR-669c-3p (highlighted in Additional file 1) differently expressed in IFN-y primed MSCs, which we validated through RT-PCR (Additional file 2). Based on their upregulation in primed MSCs, we postulated that these nine miRNAs could be involved in the known effect exerted by MSCs on microglia activation.

Exosomes derived from IFNg-primed MSCs affect genes related to the inflammatory and neuroprotective phenotype of microglia 
Exosomes were isolated from MSCs activated with IFN-y (exos ${ }^{\mathrm{IFN}-\mathrm{y}-\mathrm{MSC}}$ ) and characterized through electron microscopy and Western blot analyses. These analyses revealed a preparation composed of purified nanovesicles, with a diameter ranging from 30 to $100 \mathrm{~nm}$, which expressed ALIX and CD9 (Additional file 3) as exosomal markers [37].

To understand if exos ${ }^{\mathrm{IFN}-\mathrm{y}-\mathrm{MSC}}$ could modulate the molecular phenotype of activated microglia, we exposed LPS-activated N9 cells to exos ${ }^{I F N-y-M S C}$ for 24 hours and assessed the mRNA expression of proand anti-inflammatory markers. The results showed that exos ${ }^{\mathrm{IFN}-\mathrm{y}-\mathrm{MSC}}$ were able to significantly downregulate the expression of pro-inflammatory genes such as $\mathrm{Tnf} \| 1 \mathrm{~b}$ and $\| 18$, whilst upregulating the expression of markers associated with an anti-inflammatory/neuroprotective phenotype including Cx3cr1[38], Cd206 [39], Nr4a2 [40], on activated microglial cells (Fig. 1).

We further assessed if exos ${ }^{I F N-y-M S C}$ could affect microglia isolated from the brain of late symptomatic SOD $1^{\text {G93A }}$ mice. At this stage, these cells display an overactivated pro-inflammatory phenotype, with upregulation of Tnf expression and downregulation of alternative activation phenotype markers (Cx3cr1 and Nr4a2), as compared to microglia isolated from wtSOD1 mice (Fig. 2a). While pure microglia can be isolated from adult mouse brain, albeit with a low yield, these cells do not grow well in culture. Nevertheless, a 24-hour exposure of the primary SOD $1^{\text {G93A }}$ microglia culture to exos ${ }^{\text {IFN-y-MSC }}$ yielded data which, albeit not reaching significance, suggest that exos ${ }^{\mathrm{IFN}-\mathrm{Y}-\mathrm{MSC}}$ could modulate the pro-inflammatory phenotype of SOD ${ }^{\text {G93A }}$ microglia by inducing a decrease in Tnf expression and an increase in expression of Cx3cr1 and Nr4a2 (Fig. 2b).

\section{miRNAs dysregulated in IFNg-primed MSCs are differentially expressed in their derived exosomes}

To first ascertain if exosomes derived from IFNg-primed MSCs contain the same miRNAs dysregulated in the cells themselves (Additional File 2), we measured miRNA expression in exosomes derived from both unprimed and IFN-y-primed MSCs (Fig. 3).

The results show that all nine miRNAs are present in unprimed MSC-derived exosomes (exos ${ }^{\mathrm{MSC}}$ ). Only four of these miRNAs, namely miR-467f, miR-466q, miR-466m-5p and miR-466i-3p, are significantly upregulated in exos ${ }^{\mathrm{IFN}-\mathrm{y}-\mathrm{MSC}}$ (Fig. 3), supporting the findings of Squadrito et al. that sorting in exosomes is apparently influenced by the cellular environment [41], an observation which could be relevant in the context of their potential effect on their mRNA targets and suggesting a possible active role played by these specific miRNAs in the immunomodulatory capacity of MSCs.

\section{In-vitro transfection with specific mimics reduces the pro-inflammatory phenotype of activated microglia}


To understand if the four miRNAs upregulated in exos ${ }^{\mathrm{IFN}-\mathrm{y}-\mathrm{MSC}}$ could affect the pro-inflammatory phenotype of activated microglia, we transfected LPS-activated N9 microglia with their respective mimics (synthetically generated oligonucleotide of sequence identical with that of endogenous miRNAs), and measured the mRNA expression of the pro-inflammatory phenotype markers, Tnf and II $1 \mathrm{~b}$, and of Cx3cr1, as a marker of anti-inflammatory microglia (Fig. 4a). As expected, activation with LPS induced microglia to overexpress pro-inflammatory cytokines and to downregulate $\mathrm{Cx} 3 \mathrm{cr} 1$ expression. Transfection with mimics demonstrated that some of the miRNAs could modulate microglia phenotype; in particular, miR$467 f$ and miR-466q significantly reduced the expression of Tnf and II $1 b$, whereas miR-466m-5p induced an upregulation of $\mathrm{Cx} 3 \mathrm{cr} 1$ expression; miR-466i-3p did not have any effect.

To understand if the modulatory effect of miR-467 and miR-466q on the pro-inflammatory phenotype of LPS-activated N9 microglia-like cells translated to the SOD $1^{\mathrm{G} 93 \mathrm{~A}}$ microglia, we transfected primary microglia from late symptomatic SOD1 ${ }^{\text {G93A }}$ mice with miR-467f and miR-466q and analysed the expression of the representative pro-inflammatory genes, Tnf and II1b. In line with what we observed with LPS-activated N9 cells, transfection with miR-467f and miR-466q reduced Tnf and II $1 \mathrm{~b}$ mRNA expression in primary SOD $1^{\mathrm{G} 93 \mathrm{~A}}$ microglia (Fig. $4 \mathrm{~b}$ ).

These results suggest a selective role for specific miRNAs in microglia phenotype modulation, with miR$467 f$ and miR-466q in particular showing an anti-inflammatory potential upon transfection in activated microglia.

To assess whether miR-466i-5p, miR-467g, miR-3082-5p, miR-5126 and miR-669c-3p that were dysregulated in IFN-y-primed MSCs but not upregulated in their derived exosomes, could also have some effect on the phenotype of microglia, we transfected LPS-activated N9 microglia-like cells with mimics of these miRNAs and analysed the expression of Tnf, $\| 1 \mathrm{~b}$ and $\mathrm{Cx} 3 \mathrm{cr} 1$ in the cells by RT-PCR. The results show that miR-3082-5p and miR-5126 significantly increased the expression of $\mathrm{Cx} 3 \mathrm{cr} 1$, while none of the miRNAs was able to affect the expression of the pro-inflammatory genes (Additional file 4).

\section{miR-467f and miR-466q act on their target genes to reduce the activation of the p38 MAPK pathway and, thereby, the inflammatory phenotype of activated microglia}

Based on their anti-inflammatory effect, we further investigated the mechanism of action of miR-467f and miR-466q. To predict possible miRNA targets for these miRNAs, we used miRWalk online database, which predicts the possible targets of miRNAs through algorithms applying several different criteria, such as perfect base pairing, conservation criteria, AU content, and free energy of miRNA-mRNA heteroduplex. Hence, we identified 1718 possible target genes for miR-467f and 1157 for miR-466q (Additional files 5 and 6 , respectively). To define pathways that could involve components encoded by these target genes, we used two different databases, KEGG, which predicts pathways based on the involvement of the miRNA itself in regulating the pathway, and Panther Classification System, which predicts pathways on the basis of the predicted target genes we identified through miRWalk database. By combining data from 
these two databases, we predicted a number of pathways, listed in Table 1, which could be affected by the specific miRNAs, and we decided to focus on MAPK signaling, since this pathway can be modulated by both miRNAs (Table 2). Most importantly, since MAPKs are a family of serine/threonine kinases whose activation is correlated with the synthesis of inflammation mediators, the inhibition of this pathway by both miRNAs could explain their anti-inflammatory effect in activated microglia.

Of the several components of MAPK pathway which could be regulated by miR-467f and miR-466q (Table 2), we focused on Map3k8, target of miR-467f, and Mk2, target of miR-466q, important steps of activation of the p38 MAPK signaling pathway (Fig. 5a), which plays a key role in neuroinflammation [42]. To assess if the expression of Map3k8 and Mk2 in microglia is affected by exposure of the cells to exos ${ }^{\mathrm{IFN}-\mathrm{Y}-}$ MSC, we cultured LPS-activated N9 cells in the presence of exos ${ }^{\mathrm{IFN}-\mathrm{Y}-\mathrm{MSC}}$ for 24 hours and evaluated the expression of the two genes through RT-PCR analysis. The results show that exos ${ }^{\mathrm{IFN}-\mathrm{y}-\mathrm{MSC}}$ significantly decreased the mRNA expression of Map3k8 and Mk2 in pro-inflammatory microglia (Fig. 5b). To ascertain that Map3k8 and Mk2 are indeed specific targets of miR-467f and miR-466q in microglia, we performed RT-PCR for Map3k8 and Mk2 mRNAs on LPS-activated N9 cells transfected with the relevant mimics. As shown in Fig. 5c, transfection with miR-467f induced a downregulation of its direct target, Map3k8, in activated N9 cells, whereas transfection with miR-466q reduced not only the expression of its target Mk2, but also that of Map3k8 presumably due to an indirect mechanism still unknown.

We obtained similar results in ex-vivo experiments in SOD $1^{\mathrm{G} 93 \mathrm{~A}}$ primary microglia, in which transfection with miR-467f modulated the expression of Map3k8, which should affect the whole pathway, and of Mk2, probably due to the upstream effect on its direct target (Fig. 5a); as seen with activated N9 cells, miR$466 \mathrm{q}$ reduced the expression of both its direct target, Mk2, and Map3k8 (Fig. 5d). To confirm that miR$467 f$ and miR-466q affected the activation of p38 MAPK pathway, through their inhibition of their target gene expression, we investigated phosphorylated p38 (p-p38) through immunofluorescence analyses in LPS-activated N9 cells transfected with each miRNA separately or with a mixture of both (Fig. 6a and 6b; $\mathrm{N} 9+\mathrm{Mix}+\mathrm{LPS}$ ). The co-localized fluorescence of p-p38 with the house-keeping protein, GAPDH, in N9 cells was significantly increased upon stimulation with LPS, but when treatment with LPS was preceded by transfection with miR-467f and miR-466q, individually or together, N9 cells showed reduced levels of $p$ p38. This was specific for the action of miR- $467 f$ and miR-466q in the cells, as transfection with Cneg did not have any effect, while Cpos inhibited only the expression of GAPDH, as expected.

\section{Discussion}

Administration of MSCs, which have shown neuroprotective and immunomodulatory potential [2], is being increasingly considered as a potential treatment for neurodegenerative diseases, particularly those where microglia activation plays a key role.

There is increasing evidence that the therapeutic features of MSCs may rely on paracrine mechanisms with positive effects mediated in part by exosomes released from the administered cells [43, 44]. For example, in the rat model of stroke, intravenous treatment with MSC-derived exosomes enhanced neurite 
remodeling, neurogenesis, and angiogenesis, as demonstrated through augmented numbers of neuroblasts and endothelial cells [45]. Similarly, MSC-derived exosomes induced functional recovery of rats after traumatic brain injury [46], by promoting an increase in mature neuronal and endothelial cells and a reduction in neuroinflammatory astrocytes in the lesion [47].

In this study, we show that the therapeutic effect of IFNg-primed MSCs in the SOD $1^{\text {G93A }}$ mouse model of ALS could be mediated by their released exosomes acting on activated microglia. This can be particularly relevant in view of the well-documented non-cell autonomous nature of this disease [48, 49]. In fact, although motor neurons (MNs) are the principal target in ALS, non-neuronal cells are also involved the etiopathogenesis and it is now clear that astrocytes $[48,50]$ and microglia $[51,52]$ play a crucial role in $\mathrm{MN}$ degeneration during disease progression, mainly by regulating the pro-inflammatory milieu surrounding MNs in motor cortex and spinal cord. In particular, microglia play a primary role during the late fast-progressing phase of the disease [53,54]. Therefore, the attenuation of the pro-inflammatory microglial phenotype at this stage, as in our experiments, may in turn impact positively on MNs viability and disease progression.

There is a growing interest in exosomes as potential functional vehicles that deliver their cargo, and in particular miRNAs and proteins, to target cells [55]. For example, exosomes from mouse primary cortical neurons are enriched in miR-124a which they deliver to astrocytes leading to upregulation of glutamate transporter 1 (GLT1), a protein involved in glutamate uptake [56]. Such an observation could be of therapeutic relevance in ALS where astrocytes display a pathological downregulation of GLT1 expression. On the other hand, exosomes can also be deleterious, depending on the parent cell milieu; thus, in-vitro studies show that astrocytes derived from SOD $1^{\text {G93A }}$ mice secrete exosomes that transfer SOD $1^{\text {G93A }}$ to non-transgenic spinal neurons inducing motor neuron death, which could contribute to progression of ALS pathology [57]. This suggests that microenvironmental stimuli could affect the cargo of the exosomes released by cells, and thereby the response of the target cells. Molecular sorting into exosomes is affected by the cell milieu [58] and sorting of miRNAs in particular is regulated by the cell status, as elegantly demonstrated by Squadrito et al. [41]. In this context, we observed that priming of MSCs with IFN-y, which licenses their immunosuppressive capacity [36], induced an overexpression of specific miRNAs, suggesting their possible role in the immunomodulatory action of MSCs. Of interest, we observed differences in the levels of the studied miRNAs in the exos ${ }^{\mathrm{IFN}-\mathrm{y}-\mathrm{MSC}}$ compared to exos $^{\mathrm{MSC}}$, which did not necessarily mirror their expression in the parental cells, supporting the demonstration that exosomal content does not reflect the cytoplasm of the cell from which they originate [59] and is affected by environmental conditions, such as oxidative stress [60].

We showed that exos ${ }^{\mathrm{IFN}-\mathrm{y}-\mathrm{MSC}}$ are enriched in specific miRNAs able to modulate the pro-inflammatory phenotype of target microglial cells, a demonstration on par with other studies demonstrating functional transfer of miRNAs through exosome-shuttling, whereby miRNA-containing exosomes can affect the response of recipient cells to the environment $[58,59]$. This is of particular importance in the context of inflammation where such intercellular communication through exosome-transferred miRNAs has been shown to influence inflammatory responses $[58,61]$. This is exemplified by the study of Alexander et al. 
[62] in mice, whereby in-vivo administration of exosomes containing miRNAs with contrasting functions, miR-155 and miR-146a, altered the capacity of the recipient cells to respond to inflammatory cues in ways reflecting their respective regulatory functions. Thus, while miR-155-containing exosomes induced an increase of the cellular response to LPS with overexpression of TNF and IL-6 in serum in mice treated with LPS, administration of miR-146a-containing exosomes led to a reduction of the inflammatory response to LPS, with decreases in TNF and IL6 serum concentrations [62]. These data confirm that depending on the milieu of the parent cell and differential miRNA enrichment of the exosomes released, these could induce target cells to react to the same inflammatory stimulus in different ways.

Interestingly, in our study we noted a common "beneficial" anti-inflammatory effect on pro-inflammatory microglia exerted by transfected miR-467f and miR-466q and by exos ${ }^{\mathrm{IFN}-\mathrm{y}-\mathrm{MSC}}$ in which they are enriched, suggesting that the anti-inflammatory effect of exos ${ }^{\mathrm{IFN}-\mathrm{y}-\mathrm{MSC}}$ could be related to the miRNA content. Indeed, transfection of selected miRNAs in pro-inflammatory microglia showed that miR- $467 \mathrm{f}$ and miR$466 q$ are able to affect microglia activation, inhibiting the expression of pro-inflammatory cytokines. In this context, exosomes have been studied as modulators of neuroinflammation through the shuttling of their cargo, which includes miRNAs, to target cells [61]. Thus, it has been shown that several miRNAs play an important role in the control of neuroinflammatory mechanisms. In the animal model of traumatic brain injury, miR-200b is downregulated in pro-inflammatory microglia, but when transfected in these cells it is able to modulate the inflammatory response, decreasing c-Jun $\mathrm{N}$-terminal kinase activity, inducible nitric oxide synthase expression, and nitric oxide production [63]. However, the anti-inflammatory mode of action of transfected miRNAs does not depend necessarily on restoring their expression in the cells; indeed, activation of microglia was not associated with a decrease in the expression of miR- $467 f$ and miR-466q (additional file 7); rather, the anti-inflammatory effect of the transfected miRNAs suggests that a quantitative threshold might be necessary for their effect on the gene targets to result in a qualitative response [64].

Based on our data, we propose that exos ${ }^{I F N-y-M S C}$ can attenuate pro-inflammatory microglia phenotype through the activity of specific miRNAs able to modulate the p38 MAPK pathway which is involved in the neuroinflammatory process. An aberrant activation of p38 MAPK has been demonstrated in ALS [65], suggesting a crucial role for this pathway in the disease. In this context, the demonstration that miR-467f and miR-466q play a role in inhibiting the p38 MAPK signaling pathway could be exploited to further support the use of MSCs or MSC-derived exosomes to treat neurodegenerative diseases characterized by microglia activation, such as ALS.

\section{Conclusions}

In conclusion, we demonstrated that MSC-derived exosomes can regulate neuroinflammation through specific miRNAs that modulate the pro-inflammatory phenotype of activated microglia. In particular, we showed that miR-467f and miR-466q exert their anti-inflammatory role affecting target genes involved in

Page 14/30 
the p38 MAPK signaling pathway, which participates in the increased microglial production of proinflammatory cytokines. Therefore, this study suggests another mode of action through which MSCs can control microglia activation, and identifies possible relevant immunomodulatory miRNAs that could lead to novel therapies that dampen neuroinflammation. Our data with SOD ${ }^{\mathrm{G} 93 \mathrm{~A}}$ primary microglia support the hypothesis that MSC-derived exosomes and their delivered miRNAs can have a positive impact in experimental ALS by reducing the pro-inflammatory phenotype of microglia, possibly ameliorating the disease course.

The potential value of exosomes as therapeutic tool is increasingly promising and would provide several advantages compared to classical cell therapy, mainly linked to the ability to mitigate risks associated with cell transplantation, to cross the blood-brain barrier, which is highly impenetrable to most drugs, and to impact on the behavior of adjacent or distant cells.

In addition, exosomes are naturally carriers of miRNAs and this intrinsic property could be exploited as a gene delivery system. Moreover, one of the main advantages of using exosomes is the possibility to engineer them "made-to-order" to improve their functions, allowing the delivery of appropriate cargo, including miRNAs, directly to the brain.

\section{Declarations}

Ethics approval:

The research protocols were approved by the Animal Ethics Committee of Ospedale Policlinico San Martino, the Ethical Committee for Animal Experimentation of the University of Genoa, Italy, and the Italian Ministry of Health (Project No. 384, authorization 230/2016-PR and Project No. 75f11.3, Authorization No.482/2017-PR).

Consent for publication

Not applicable

Availability of data and materials

All data generated or analysed during this study are included in this published article and its supplementary information files.

Competing interests:

The authors declare that they have no competing interests.

Funding:

This work was supported in part by the AriSLA Foundation No. PGBR 03/2013

Contributions:

All authors had full access to all the data in the study and take responsibility for the integrity of the data and the accuracy of the data analysis.

Acknowledgements:

We thank Prof. Alberto Diaspro for making the confocal microscope (Department of Physics, University of Genoa) available to us. 


\section{Abbreviations}

MSC: mesenchymal stem cell

ALS: amyotrophic lateral sclerosis

miRNA: microRNA

IFN-ץ: interferon-gamma

LPS: lipopolysaccharide

SOD1 ${ }^{\text {G93A: }}$ mutated SOD1

FBS: fetal bovine serum

wtSOD1: wild type SOD1

exos $^{\mathrm{IFN}-\mathrm{Y}-\mathrm{MSC}}$ : IFN-Y-primed MSC-derived exosomes

RT-PCR: real time polymerase chain reaction

Tnf: tumor necrosis factor

II: interleukin

$\mathrm{Nr} 4 a 2$ : nuclear receptor subfamily 4 group $\mathrm{A}$

Cd206: cluster of differentiation 206

Map3k8: mitogen-activated protein kinase kinase kinase 8

Mk2: mitogen-activated protein kinase activated protein kinase 2

exos $^{\mathrm{MSC}}$ : unstimulated MSC-derived exosomes

MAPK: mitogen-activated protein kinase

p-p38: phosphorylated p38

\section{References}

1. Di Nicola M, Carlo-Stella C, Magni M, Milanesi M, Longoni PD, Matteucci P, Grisanti S, Gianni AM: Human bone marrow stromal cells suppress T-lymphocyte proliferation induced by cellular or 
nonspecific mitogenic stimuli. Blood 2002, 99:3838-3843. DOI: 10.1182/blood.v99.10.3838 .

2. Uccelli A, Moretta L, Pistoia V: Mesenchymal stem cells in health and disease. Nat Rev Immunol 2008, 8:726-736. DOI: 10.1038/nri2395.

3. Najar M, Raicevic G, Id Boufker H, Stamatopoulos B, De Bruyn C, Meuleman N, Bron D, Toungouz M, Lagneaux $L$ : Modulated expression of adhesion molecules and galectin-1: role during mesenchymal stromal cell immunoregulatory functions. Exp Hematol 2010, 38:922-932. DOI:

10.1016/j.exphem.2010.05.007.

4. Sioud M, Mobergslien A, Boudabous A, Fløisand Y: Evidence for the involvement of galectin-3 in mesenchymal stem cell suppression of allogeneic T-cell proliferation. Scand J Immuno/ 2010, 71:267-274. DOI: 10.1111/j.1365-3083.2010.02378.x.

5. Noh MY, Lim SM, Oh KW, Cho KA, Park J, Kim KS, Lee SJ, Kwon MS, Kim SH: Mesenchymal Stem Cells Modulate the Functional Properties of Microglia via TGF- $\beta$ Secretion. Stem Cells Trans/ Med 2016, 5:1538-1549. DOI: 10.5966/sctm.2015-0217.

6. Liu Y, Zhang R, Yan K, Chen F, Huang W, Lv B, Sun C, Xu L, Li F, Jiang X: Mesenchymal stem cells inhibit lipopolysaccharide-induced inflammatory responses of BV2 microglial cells through TSG-6. $J$ Neuroinflammation 2014, 11:135. DOI: 10.1186/1742-2094-11-135.

7. Neubrand VE, Pedreno M, Caro M, Forte-Lago I, Delgado M, Gonzalez-Rey E: Mesenchymal stem cells induce the ramification of microglia via the small RhoGTPases Cdc42 and Rac1. Glia 2014, 62:19321942. DOI: $10.1002 /$ glia.22714.

8. Giunti D, Parodi B, Usai C, Vergani L, Casazza S, Bruzzone S, Mancardi G, Uccelli A: Mesenchymal stem cells shape microglia effector functions through the release of CX3CL1. Stem Cells 2012, 30:2044-2053. DOI: 10.1002/stem.1174.

9. Jaimes Y, Naaldijk Y, Wenk K, Leovsky C, Emmrich F: Mesenchymal Stem Cell-Derived Microvesicles Modulate Lipopolysaccharides-Induced Inflammatory Responses to Microglia Cells. Stem Cells 2017, 35:812-823. DOI: 10.1002/stem.2541.

10. Laroni A, Kerlero de Rosbo N, Uccelli A: Mesenchymal stem cells for the treatment of neurological diseases: Immunoregulation beyond neuroprotection. Immunol Lett 2015, 168:183-190. DOI: 10.1016/j.imlet.2015.08.007.

11. Zappia E, Casazza S, Pedemonte E, Benvenuto F, Bonanni I, Gerdoni E, Giunti D, Ceravolo A, Cazzanti F, Frassoni $F$, et al: Mesenchymal stem cells ameliorate experimental autoimmune encephalomyelitis inducing T-cell anergy. Blood 2005, 106:1755-1761. DOI: 10.1182/blood-2005-04-1496.

12. Lovato L, Rosbo N, Uccelli A: Mesenchymal Stem Cells for the Treatment of Multiple Sclerosis. Multiple Sclerosis Immunology: A Foundation for Current and Future Treatments 2013:433-455. DOI: 10.1007/978-1-4614-7953-6_20.

13. Uccelli A, Milanese M, Principato MC, Morando S, Bonifacino T, Vergani L, Giunti D, Voci A, Carminati E, Giribaldi F, et al: Intravenous mesenchymal stem cells improve survival and motor function in experimental amyotrophic lateral sclerosis. Mol Med 2012, 18:794-804. DOI:

10.2119/molmed.2011.00498. 
14. Bonafede R, Mariotti R: ALS Pathogenesis and Therapeutic Approaches: The Role of Mesenchymal Stem Cells and Extracellular Vesicles. Front Cell Neurosci 2017, 11:80. DOI:

10.3389/fncel.2017.00080.

15. Lewis CM, Suzuki M: Therapeutic applications of mesenchymal stem cells for amyotrophic lateral sclerosis. Stem Cell Res Ther 2014, 5:32. DOI: 10.1186/scrt421.

16. Vercelli A, Mereuta OM, Garbossa D, Muraca G, Mareschi K, Rustichelli D, Ferrero I, Mazzini L, Madon E, Fagioli F: Human mesenchymal stem cell transplantation extends survival, improves motor performance and decreases neuroinflammation in mouse model of amyotrophic lateral sclerosis. Neurobiol Dis 2008, 31:395-405. DOI: 10.1016/j.nbd.2008.05.016.

17. Sun H, Hou Z, Yang H, Meng M, Li P, Zou Q, Yang L, Chen Y, Chai H, Zhong H, et al: Multiple systemic transplantations of human amniotic mesenchymal stem cells exert therapeutic effects in an ALS mouse model. Cell Tissue Res 2014, 357:571-582. DOI: 10.1007/s00441-014-1903-z.

18. Raposo G, Stoorvogel W: Extracellular vesicles: exosomes, microvesicles, and friends. J Cell Biol 2013, 200:373-383. DOI: 10.1083/jcb.201211138.

19. Lai RC, Arslan F, Lee MM, Sze NS, Choo A, Chen TS, Salto-Tellez M, Timmers L, Lee CN, El Oakley RM, et al: Exosome secreted by MSC reduces myocardial ischemia/reperfusion injury. Stem Cell Res 2010, 4:214-222. DOI: 10.1016/j.scr.2009.12.003.

20. Xin H, Li Y, Buller B, Katakowski M, Zhang Y, Wang X, Shang X, Zhang ZG, Chopp M: Exosomemediated transfer of miR-133b from multipotent mesenchymal stromal cells to neural cells contributes to neurite outgrowth. Stem Cells 2012, 30:1556-1564. DOI: 10.1002/stem.1129.

21. Villarroya-Beltri C, Baixauli F, Gutiérrez-Vázquez C, Sánchez-Madrid F, Mittelbrunn M: Sorting it out: regulation of exosome loading. Semin Cancer Bio/ 2014, 28:3-13. DOI:

10.1016/j.semcancer.2014.04.009.

22. Catalanotto C, Cogoni C, Zardo G: MicroRNA in Control of Gene Expression: An Overview of Nuclear Functions. Int J Mol Sci 2016, 17. DOI: 10.3390/ijms17101712.

23. Vigo T, Procaccini C, Ferrara G, Baranzini S, Oksenberg JR, Matarese G, Diaspro A, Kerlero de Rosbo $\mathrm{N}$, Uccelli A: IFN-y orchestrates mesenchymal stem cell plasticity through the signal transducer and activator of transcription 1 and 3 and mammalian target of rapamycin pathways. J Allergy Clin Immunol 2017, 139:1667-1676. DOI: 10.1016/j.jaci.2016.09.004.

24. Brazma A, Hingamp P, Quackenbush J, Sherlock G, Spellman P, Stoeckert C, Aach J, Ansorge W, Ball CA, Causton HC, et al: Minimum information about a microarray experiment (MIAME)-toward standards for microarray data. Nat Genet 2001, 29:365-371. DOI: 10.1038/ng1201-365.

25. Bianco F, Pravettoni E, Colombo A, Schenk U, Möller T, Matteoli M, Verderio C: Astrocyte-derived ATP induces vesicle shedding and IL-1 beta release from microglia. J Immuno/ 2005, 174:7268-7277. DOI: 10.4049/jimmunol.174.11.7268.

26. Théry C, Amigorena S, Raposo G, Clayton A: Isolation and characterization of exosomes from cell culture supernatants and biological fluids. Curr Protoc Cell Bio/ 2006, Chapter 3:Unit 3.22. DOI: 10.1002/0471143030.cb0322s30. 
27. Gurney ME, Pu H, Chiu AY, Dal Canto MC, Polchow CY, Alexander DD, Caliendo J, Hentati A, Kwon YW, Deng HX: Motor neuron degeneration in mice that express a human $\mathrm{Cu}, \mathrm{Zn}$ superoxide dismutase mutation. Science 1994, 264:1772-1775. DOI: 10.1126/science.8209258.

28. Vinsant S, Mansfield C, Jimenez-Moreno R, Del Gaizo Moore V, Yoshikawa M, Hampton TG, Prevette D, Caress J, Oppenheim RW, Milligan C: Characterization of early pathogenesis in the SOD1(G93A) mouse model of ALS: part II, results and discussion. Brain Behav 2013, 3:431-457. DOI: 10.1002/brb3.142.

29. Philips T, Robberecht W: Neuroinflammation in amyotrophic lateral sclerosis: role of glial activation in motor neuron disease. Lancet Neurol 2011, 10:253-263. DOI: 10.1016/S1474-4422(11)70015-1.

30. Cardona AE, Huang D, Sasse ME, Ransohoff RM: Isolation of murine microglial cells for RNA analysis or flow cytometry. Nat Protoc 2006, 1:1947-1951. DOI: 10.1038/nprot.2006.327.

31. Manders E, Verbbek F, Aten J: Measurement of colocalization of objects in dual-colour confocal images. Jouranl of Microscopy 1993, 169. . DOI 10.1111/j.1365-2818.1993.tb03313.x.

32. Costes SV, Daelemans D, Cho EH, Dobbin Z, Pavlakis G, Lockett S: Automatic and quantitative measurement of protein-protein colocalization in live cells. Biophys $J$ 2004, 86:3993-4003. DOI: $10.1529 /$ biophysj. 103.038422.

33. Ren G, Zhang L, Zhao X, Xu G, Zhang Y, Roberts Al, Zhao RC, Shi Y: Mesenchymal stem cell-mediated immunosuppression occurs via concerted action of chemokines and nitric oxide. Cell Stem Cel/ 2008, 2:141-150. DOI: 10.1016/j.stem.2007.11.014.

34. Krampera M: Mesenchymal stromal cell 'licensing': a multistep process. Leukemia 2011, 25:14081414. DOI: 10.1038/leu.2011.108.

35. Stagg J, Pommey S, Eliopoulos N, Galipeau J: Interferon-gamma-stimulated marrow stromal cells: a new type of nonhematopoietic antigen-presenting cell. Blood 2006, 107:2570-2577. DOI: 10.1182/blood-2005-07-2793.

36. Krampera M, Cosmi L, Angeli R, Pasini A, Liotta F, Andreini A, Santarlasci V, Mazzinghi B, Pizzolo G, Vinante $F$, et al: Role for interferon-gamma in the immunomodulatory activity of human bone marrow mesenchymal stem cells. Stem Cells 2006, 24:386-398. DOI: 10.1634/stemcells.2005-0008.

37. Mathivanan S, Fahner CJ, Reid GE, Simpson RJ: ExoCarta 2012: database of exosomal proteins, RNA and lipids. Nucleic Acids Res 2012, 40:D1241-1244. DOI: 10.1093/nar/gkr828.

38. Cardona AE, Pioro EP, Sasse ME, Kostenko V, Cardona SM, Dijkstra IM, Huang D, Kidd G, Dombrowski S, Dutta R, et al: Control of microglial neurotoxicity by the fractalkine receptor. Nat Neurosci 2006 , 9:917-924. DOI: 10.1038/nn1715.

39. Cherry JD, Olschowka JA, O'Banion MK: Neuroinflammation and M2 microglia: the good, the bad, and the inflamed. $J$ Neuroinflammation 2014, 11:98. DOI: 10.1186/1742-2094-11-98.

40. Saijo K, Winner B, Carson CT, Collier JG, Boyer L, Rosenfeld MG, Gage FH, Glass CK: A Nurr1/CoREST pathway in microglia and astrocytes protects dopaminergic neurons from inflammation-induced death. Cel/2009, 137:47-59. DOI: 10.1016/j.cell.2009.01.038. 
41. Squadrito ML, Baer C, Burdet F, Maderna C, Gilfillan GD, Lyle R, Ibberson M, De Palma M: Endogenous RNAs modulate microRNA sorting to exosomes and transfer to acceptor cells. Cell Rep 2014, 8:14321446. DOI: 10.1016/j.celrep.2014.07.035.

42. Bachstetter AD, Xing B, de Almeida L, Dimayuga ER, Watterson DM, Van Eldik LJ: Microglial p38a MAPK is a key regulator of proinflammatory cytokine up-regulation induced by toll-like receptor (TLR) ligands or beta-amyloid (Aß). J Neuroinflammation 2011, 8:79. DOI: 10.1186/1742-2094-8-79.

43. Xin H, Li Y, Chopp M: Exosomes/miRNAs as mediating cell-based therapy of stroke. Front Cell Neurosci 2014, 8:377. DOI: 10.3389/fncel.2014.00377.

44. Ferguson SW, Wang J, Lee CJ, Liu M, Neelamegham S, Canty JM, Nguyen J: The microRNA regulatory landscape of MSC-derived exosomes: a systems view. Sci Rep 2018, 8:1419. DOI: 10.1038/s41598-018-19581-x.

45. Xin H, Li Y, Cui Y, Yang JJ, Zhang ZG, Chopp M: Systemic administration of exosomes released from mesenchymal stromal cells promote functional recovery and neurovascular plasticity after stroke in rats. J Cereb Blood Flow Metab 2013, 33:1711-1715. DOI: 10.1038/jcbfm.2013.152.

46. Zhang Y, Chopp M, Meng Y, Katakowski M, Xin H, Mahmood A, Xiong Y: Effect of exosomes derived from multipluripotent mesenchymal stromal cells on functional recovery and neurovascular plasticity in rats after traumatic brain injury. $J$ Neurosurg 2015, 122:856-867. DOI:

10.3171/2014.11.JNS14770.

47. Zhang Y, Chopp M, Zhang ZG, Katakowski M, Xin H, Qu C, Ali M, Mahmood A, Xiong Y: Systemic administration of cell-free exosomes generated by human bone marrow derived mesenchymal stem cells cultured under 2D and 3D conditions improves functional recovery in rats after traumatic brain injury. Neurochem Int 2017, 111:69-81. DOI: 10.1016/j.neuint.2016.08.003.

48. Haidet-Phillips AM, Hester ME, Miranda CJ, Meyer K, Braun L, Frakes A, Song S, Likhite S, Murtha MJ, Foust KD, et al: Astrocytes from familial and sporadic ALS patients are toxic to motor neurons. Nat Biotechnol 2011, 29:824-828. DOI: 10.1038/nbt.1957.

49. Ilieva H, Polymenidou M, Cleveland DW: Non-cell autonomous toxicity in neurodegenerative disorders: ALS and beyond. J Cell Bio/2009, 187:761-772. DOI: 10.1083/jcb.200908164.

50. Yamanaka K, Chun SJ, Boillee S, Fujimori-Tonou N, Yamashita H, Gutmann DH, Takahashi R, Misawa $\mathrm{H}$, Cleveland DW: Astrocytes as determinants of disease progression in inherited amyotrophic lateral sclerosis. Nat Neurosci 2008, 11:251-253. DOI: 10.1038/nn2047.

51. Boillee S, Yamanaka K, Lobsiger CS, Copeland NG, Jenkins NA, Kassiotis G, Kollias G, Cleveland DW: Onset and progression in inherited ALS determined by motor neurons and microglia. Science 2006, 312:1389-1392. DOI: 10.1126/science.1123511.

52. Frakes AE, Ferraiuolo L, Haidet-Phillips AM, Schmelzer L, Braun L, Miranda CJ, Ladner KJ, Bevan AK, Foust KD, Godbout JP, et al: Microglia induce motor neuron death via the classical NF-kappaB pathway in amyotrophic lateral sclerosis. Neuron 2014, 81:1009-1023. DOI:

10.1016/j.neuron.2014.01.013. 
53. Henkel JS, Beers DR, Zhao W, Appel SH: Microglia in ALS: the good, the bad, and the resting. $J$ Neuroimmune Pharmacol 2009, 4:389-398. DOI: 10.1007/s11481-009-9171-5.

54. Geloso MC, Corvino V, Marchese E, Serrano A, Michetti F, D'Ambrosi N: The Dual Role of Microglia in ALS: Mechanisms and Therapeutic Approaches. Front Aging Neurosci 2017, 9:242. DOI: 10.3389/fnagi.2017.00242.

55. Momen-Heravi F, Bala S, Bukong T, Szabo G: Exosome-mediated delivery of functionally active miRNA-155 inhibitor to macrophages. Nanomedicine 2014, 10:1517-1527. DOI: 10.1016/j.nano.2014.03.014.

56. Morel L, Regan M, Higashimori H, Ng SK, Esau C, Vidensky S, Rothstein J, Yang Y: Neuronal exosomal miRNA-dependent translational regulation of astroglial glutamate transporter GLT1. J Biol Chem 2013, 288:7105-7116. DOI: 10.1074/jbc.M112.410944.

57. Basso M, Pozzi S, Tortarolo M, Fiordaliso F, Bisighini C, Pasetto L, Spaltro G, Lidonnici D, Gensano F, Battaglia E, et al: Mutant copper-zinc superoxide dismutase (SOD1) induces protein secretion pathway alterations and exosome release in astrocytes: implications for disease spreading and motor neuron pathology in amyotrophic lateral sclerosis. J Biol Chem 2013, 288:15699-15711. DOI: 10.1074/jbc.M112.425066.

58. Robbins PD, Dorronsoro A, Booker CN: Regulation of chronic inflammatory and immune processes by extracellular vesicles. J Clin Invest 2016, 126:1173-1180. DOI: 10.1172/JCl81131.

59. Valadi H, Ekström K, Bossios A, Sjöstrand M, Lee JJ, Lötvall JO: Exosome-mediated transfer of mRNAs and microRNAs is a novel mechanism of genetic exchange between cells. Nat Cell Bio/ 2007, 9:654-659. DOI: 10.1038/ncb1596.

60. Eldh M, Ekström K, Valadi H, Sjöstrand M, Olsson B, Jernås M, Lötvall J: Exosomes communicate protective messages during oxidative stress; possible role of exosomal shuttle RNA. PLoS One 2010, 5:e15353. DOI: 10.1371/journal.pone.0015353.

61. Gupta A, Pulliam L: Exosomes as mediators of neuroinflammation. J Neuroinflammation 2014, 11:68. DOI: 10.1186/1742-2094-11-68.

62. Alexander M, Hu R, Runtsch MC, Kagele DA, Mosbruger TL, Tolmachova T, Seabra MC, Round JL, Ward DM, O'Connell RM: Exosome-delivered microRNAs modulate the inflammatory response to endotoxin. Nat Commun 2015, 6:7321. DOI: 10.1038/ncomms8321.

63. Jadhav SP, Kamath SP, Choolani M, Lu J, Dheen ST: microRNA-200b modulates microglia-mediated neuroinflammation via the cJun/MAPK pathway. J Neurochem 2014, 130:388-401. DOI: 10.1111/jnc. 12731.

64. Yu A, Zhang T, Duan H, Pan Y, Zhang X, Yang G, Wang J, Deng Y, Yang Z: MiR-124 contributes to M2 polarization of microglia and confers brain inflammatory protection via the C/EBP-a pathway in intracerebral hemorrhage. Immunol Lett 2017, 182:1-11. DOI: 10.1016/j.imlet.2016.12.003.

65. Bendotti C, Bao Cutrona M, Cheroni C, Grignaschi G, Lo Coco D, Peviani M, Tortarolo M, Veglianese P, Zennaro $\mathrm{E}$ : Inter- and intracellular signaling in amyotrophic lateral sclerosis: role of p38 mitogenactivated protein kinase. Neurodegener Dis 2005, 2:128-134. DOI: 10.1159/000089617. 


\section{Tables}

Table 1. Pathways predicted to be affected by miR-467f and miR-466q.

\begin{tabular}{|c|c|}
\hline \multicolumn{2}{|c|}{ miR-467f } \\
\hline Pathways in cancer & Dorso ventral axis formation \\
\hline TGF beta signaling pathway & Adipocytokine signaling pathway \\
\hline Endometrial cancer & Vascular smooth muscle contraction \\
\hline Acute myeloid leukemia & Wnt signaling pathway \\
\hline Chronic myeloid leukemia & Regulation of actin cytoskeleton \\
\hline Colorectal cancer & Ubiquitin mediated proteolysis \\
\hline MAPK signaling pathway & Melanoma \\
\hline B cell receptor signaling pathway & Glioma \\
\hline ErbB signaling pathway & Basal cell carcinoma \\
\hline Prostate cancer & Fc epsilon RI signaling pathway \\
\hline Renal cell carcinoma & Jak STAT signaling pathway \\
\hline Chemokine signaling pathway & GnRH signaling pathway \\
\hline T cell receptor signaling pathway & \\
\hline Sphingolipid metabolism & \\
\hline
\end{tabular}

\begin{tabular}{|c|}
\hline miR-466q \\
\hline Pathways in cancer \\
\hline Neurotrophin signaling pathway \\
\hline Colorectal cancer \\
\hline Endometrial cancer \\
\hline Amyotrophic lateral sclerosis \\
\hline MAPK signaling pathway \\
\hline Thyroid cancer \\
\hline VEGF signaling pathway \\
\hline Fc epsilon RI signaling pathway \\
\hline
\end{tabular}


Table 2. Components of the MAPK signaling pathway which are predicted target genes of miR-467f and miR466q.

\begin{tabular}{|c|c|}
\hline \multicolumn{2}{|c|}{ MAPK signaling pathway } \\
\hline Target of miR-467f & Target of miR-466q \\
\hline Eif4ebp1 & Mapk11/p38beta \\
\hline Mapkapk3/Mk3 & Mapkapk1c \\
\hline Il1r type 1 & Mapkapk2/Mk2 \\
\hline Mapk3/Erk1 & \\
\hline Map3k8 & \\
\hline
\end{tabular}

\section{Figures}


Figure 1
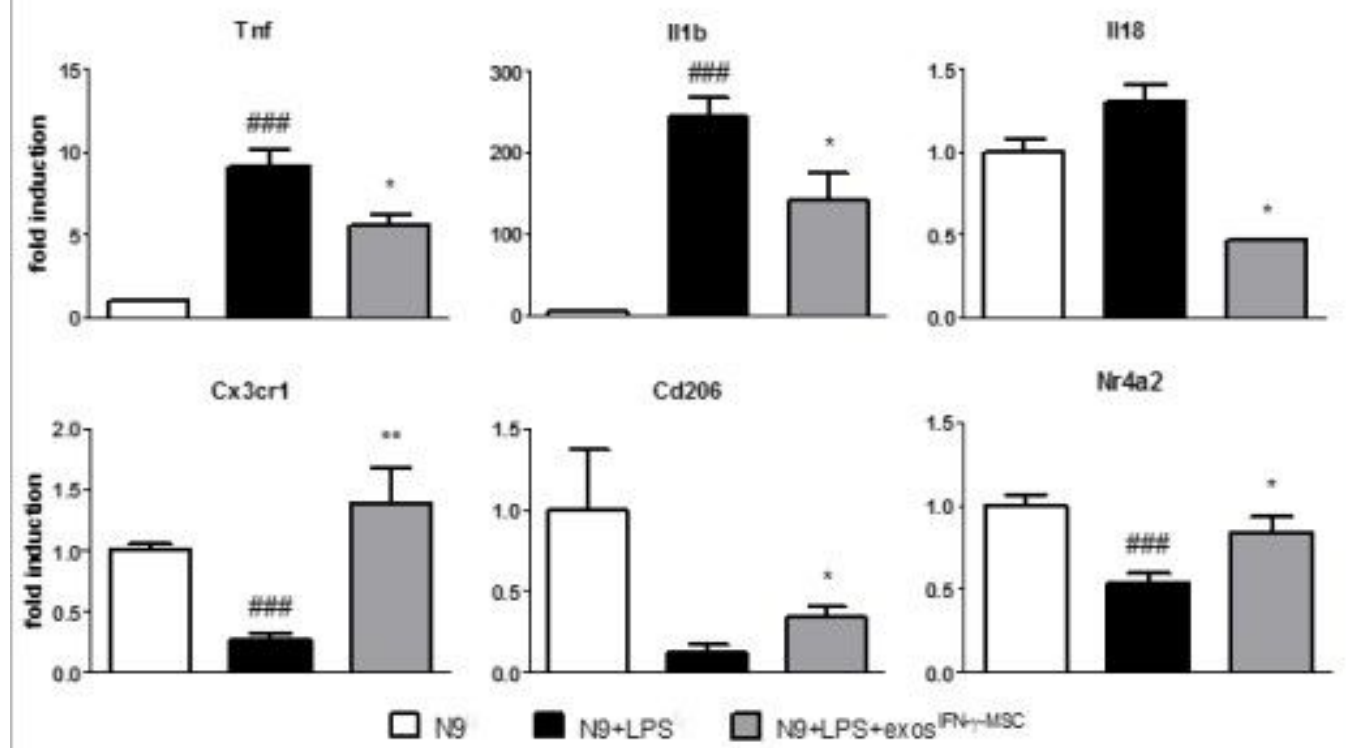

\section{Figure 1}

Exposure to exosIFN-Y-MSC affects the molecular phenotype of activated microglia. RT-PCR quantification of genes associated with a pro- (Tnf, II1 b and II18) and anti-inflammatory/neuroprotective (Cx3cr1, Cd206 and Nr4a2) phenotype in LPS-activated N9 cells. \#\#\#P < 0.001, untreated (N9) vs LPSactivated N9 cells (N9+LPS); $* \mathrm{P}<0.05, * * P<0.01$, N9+LPS vs N9+LPS exposed to exosIFN-y-MSC (N9+LPS+exosIFN- $\gamma-M S C)$. Data are presented as mean \pm SEM of 3 experiments. 


\section{Figure 2}
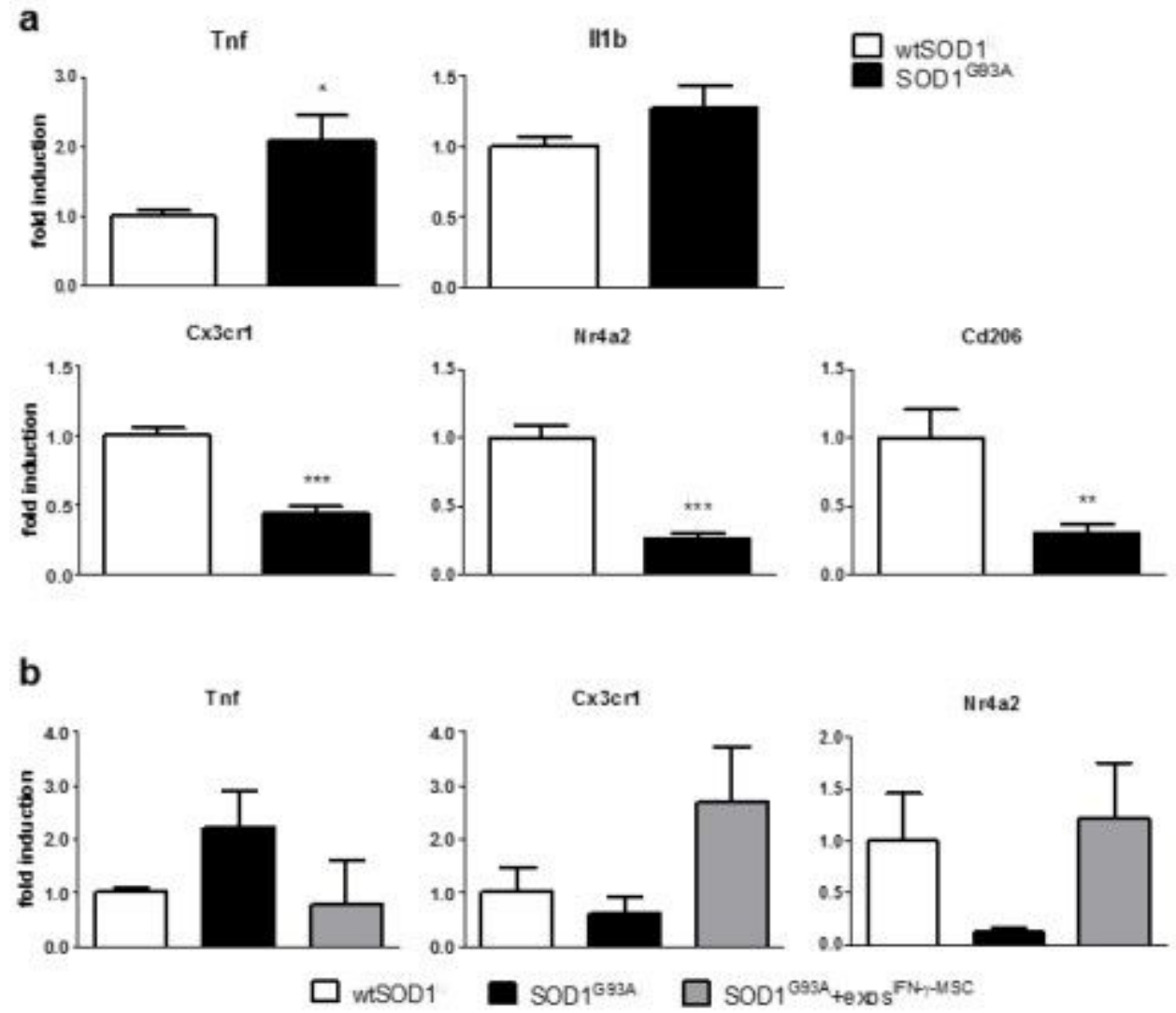

Figure 2

Exposure to exosIFN-y-MSC affects the overactivated phenotype of SOD1G93A primary microglia. a RTPCR quantification of pro-inflammatory (Tnf and II1b) and anti-inflammatory genes (Cx3cr1, Nr4a2, Cd206) in wtSOD1 and SOD1G93A primary microglia. b RT-PCR quantification of exposure to exosIFN- $y-$ MSC on Tnf and II1 b and on genes associated with an anti-inflammatory/neuroprotective phenotype (Cx3cr1, Nr4a2) in SOD1G93A primary microglia. Data are presented as mean \pm SEM of 3 (a) and 2 (b) experiments. 


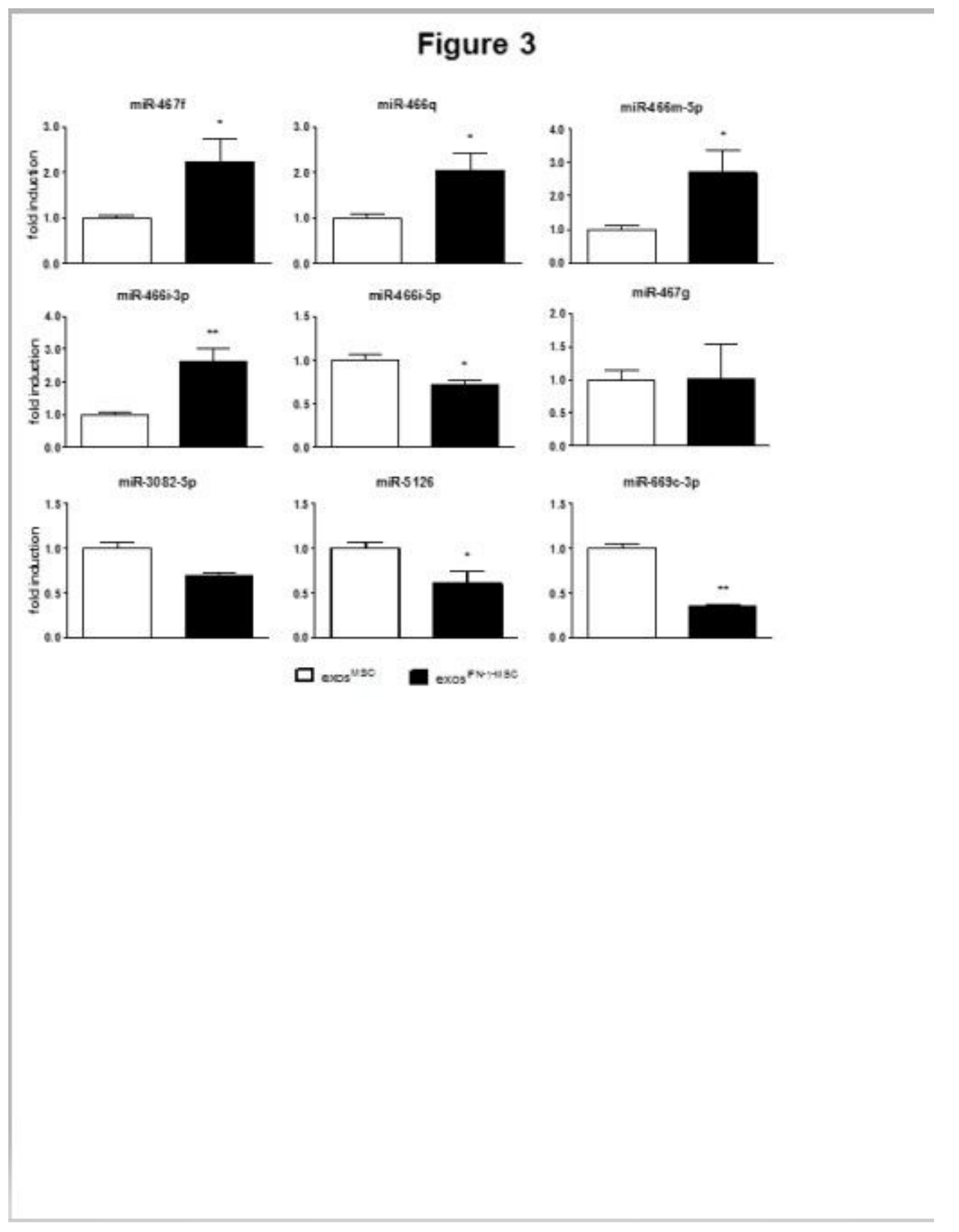

Figure 3

Exosomes derived from MSCs primed or not with IFN-y are differentially enriched in miRNAs. RT-PCR quantification of miRNAs shown by microarray to be dysregulated in immunomodulatory MSCs. ${ }^{*}<<$ 0.05 and ${ }^{* *} \mathrm{P}<0.01$, exosMSC vs exosIFN-Y-MSC. Data are presented as mean \pm SEM of 3 experiments. 
Figure 4
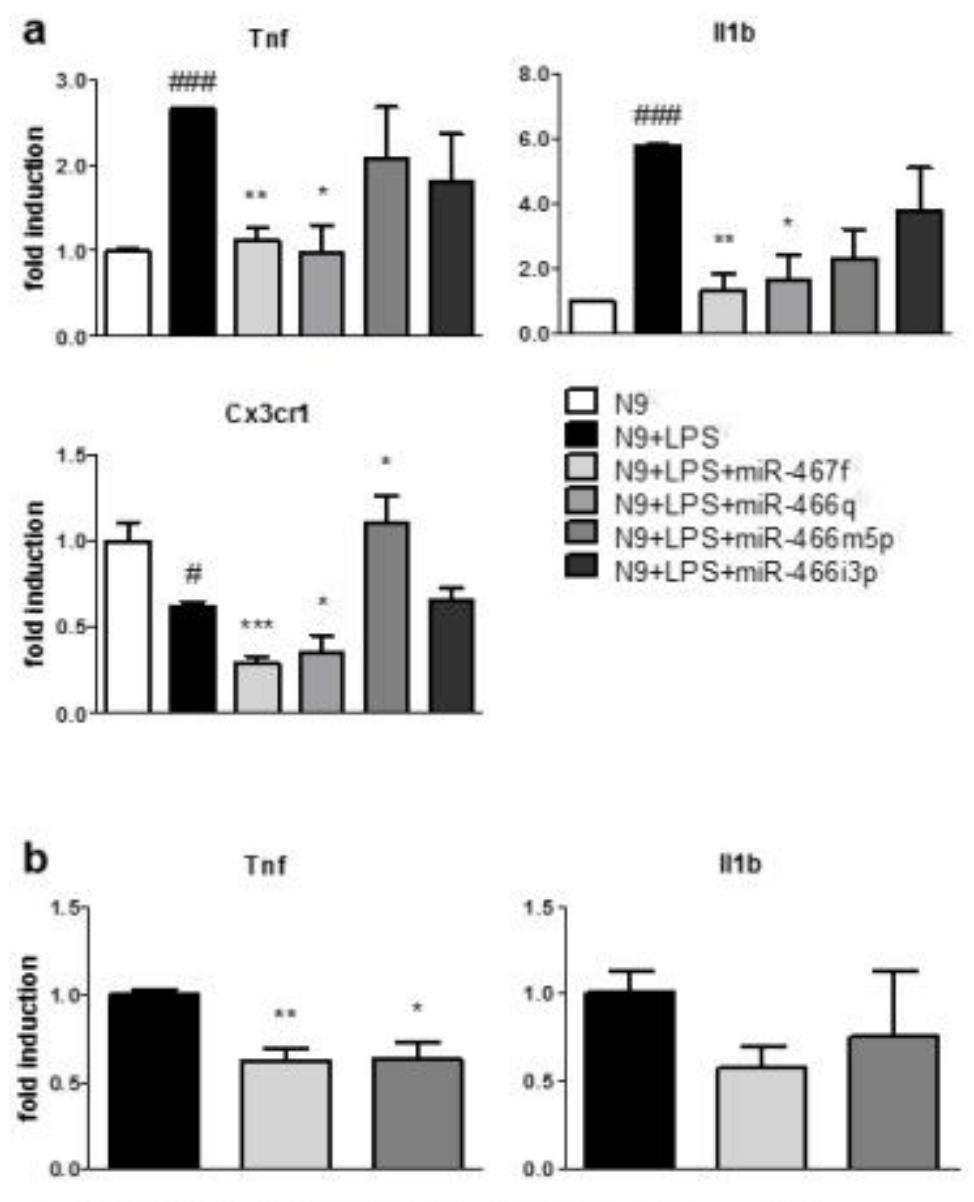

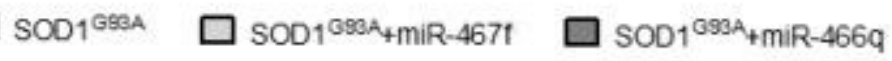

\section{Figure 4}

Transfection with specific miRNA mimics induces changes in the pro-inflammatory phenotype of activated microglia. RT-PCR analysis of markers relevant to microglia activation. LPS-activated N9 cells (a) and primary SOD1G93A microglia (b) were transfected for 24 hours with synthetic mimics of the four miRNAs as indicated in Methods. \#\#P < 0.01, untreated (N9) vs LPS-activated N9 cells (N9+LPS); \#\#\#P< 0.001 , N9 vs N9+LPS; *P < 0.05, N9+LPS vs N9+LPS transfected with specific miRNA (N9+LPS+miRNA); $\star * P<0.01, N 9+L P S$ vs N9+LPS+miRNA; $* * * P<0.001$, N9+LPS vs N9+LPS+miRNA. Data are presented as mean \pm SEM of 2 experiments. 
Figure 5
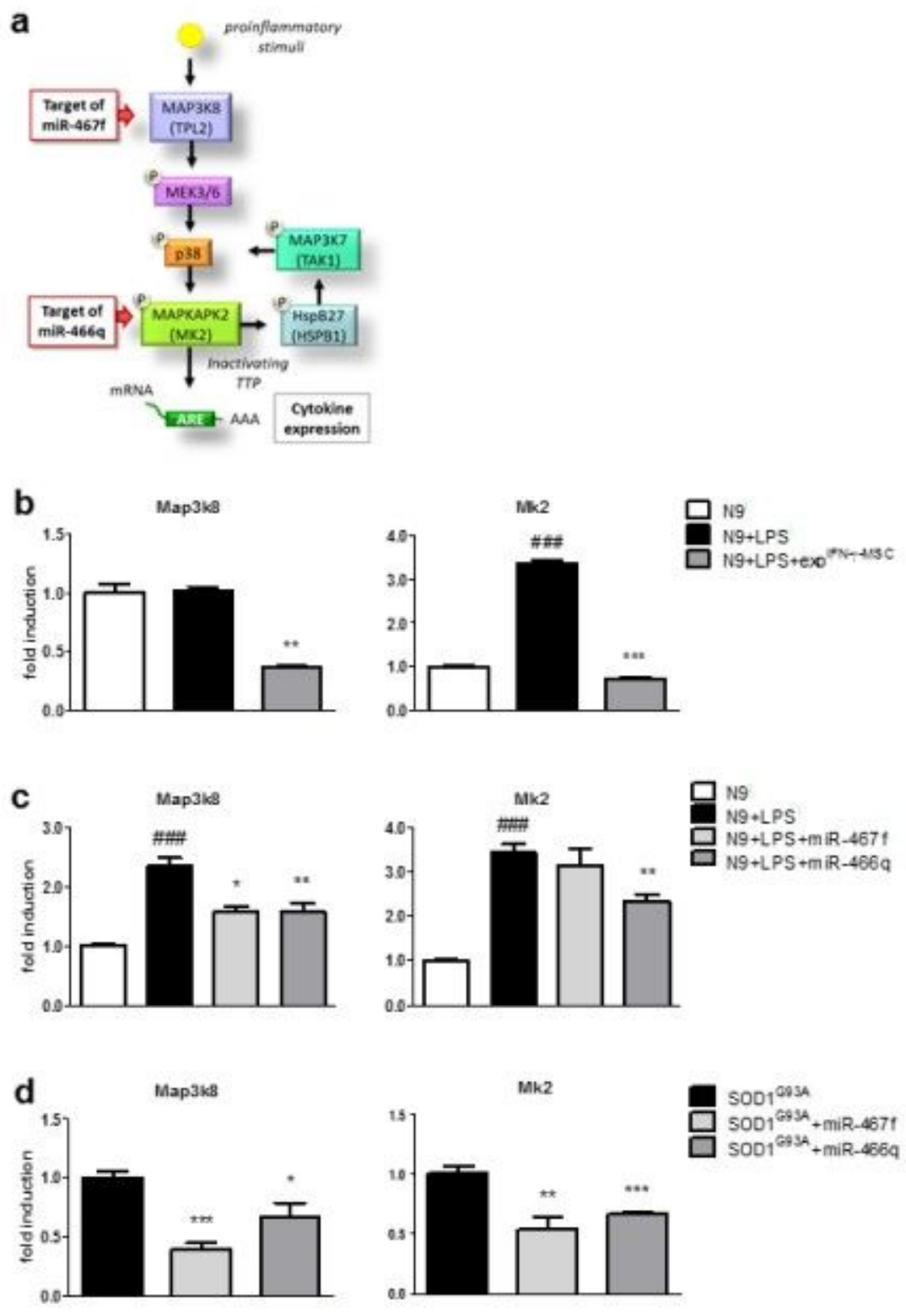

Figure 5

Transfection of microglia with miR-467f, miR-466q, or exposure to exosIFN-y-MSC, inhibits Map3k8 and Mk2 expression. a Scheme of p38 MAPK signaling pathway showing that Map3k8 and Mk2 are specific targets of miR-467f and miR-466q, respectively. $b$ Exposure of LPS-activated N9 cells to exosIFN- $y-M S C$ induced a significantly downregulation of Map3k8 and Mk2 mRNA expression. \#\#\#P $<0.001$, untreated (N9) vs LPS-activated N9 cells (N9+LPS); **P $<0.01$, $* \star * P<0.001$, N9+LPS vs N9+LPS exposed to exosIFN-y-MSC (N9+LPS+ exosIFN-y-MSC). c Downregulation of Map3k8 and Mk2 mRNA expression in LPS-activated N9 cells transfected with miR-467f and miR-466q confirm that they are target genes for these miRNAs. \#\#\#P< 0.001, untreated (N9) vs LPS-activated N9 cells (N9+LPS); $P^{2}<0.05,{ }^{\star *} P<0.01$, N9+LPS vs N9+LPS transfected with specific miRNA (N9+LPS+ miRNA). d Primary microglia transfected 
with miR-467f and miR-466q showed a significant downregulation of the expression of genes involved in the p38 MAPK signaling pathway. ${ }^{P}<0.05, * * P<0.01$, $* \star * P<0.001$, SOD1G93A microglia (SOD1G93A) vs SOD1G93A microglia transfected with specific mimic (SOD1G93A+miRNA). Data are presented as mean \pm SEM of 2 (a), 2 (b) and 3 (c) experiments.

\section{Figure 6}

a
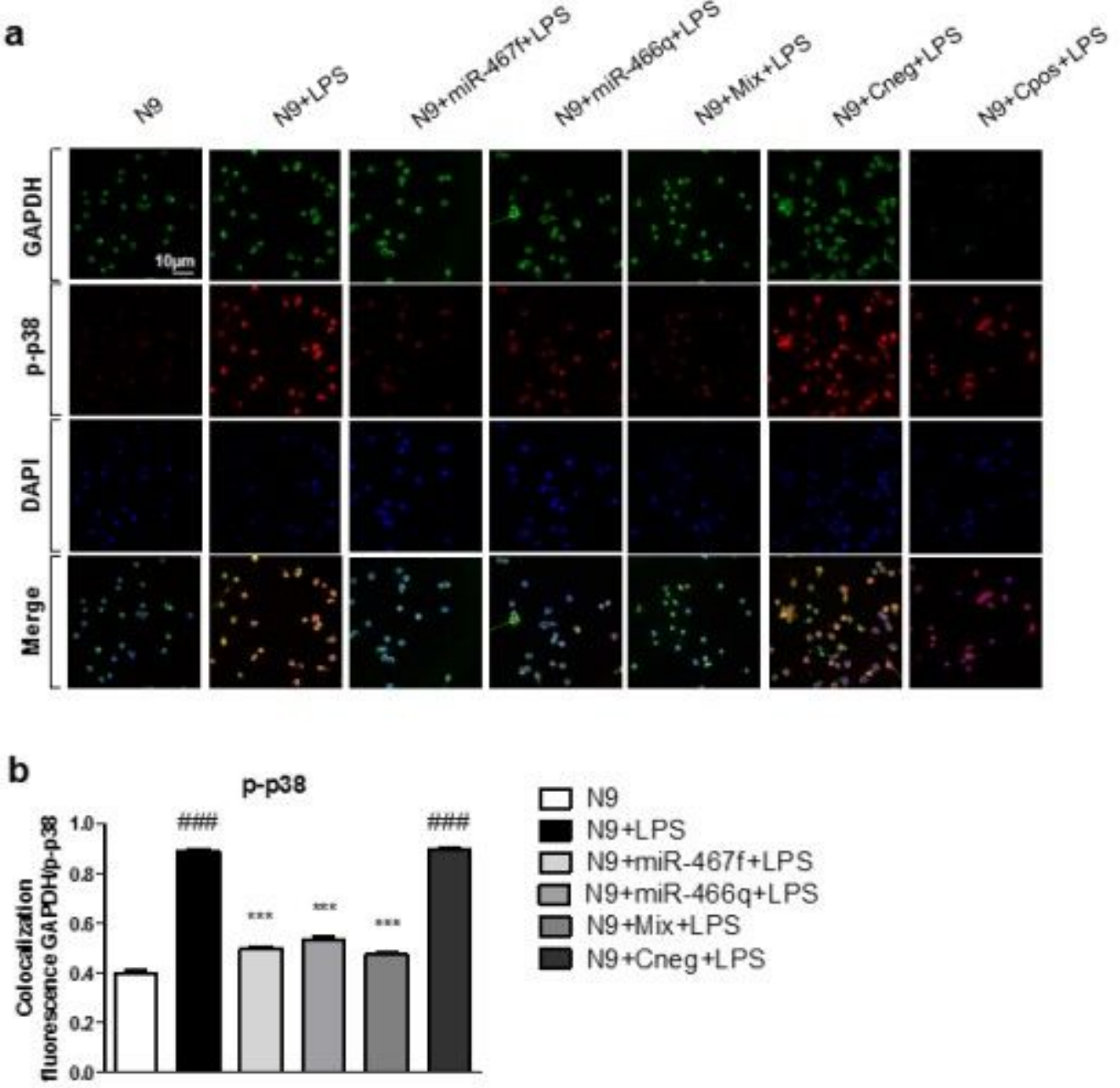

\section{Figure 6}

Activation of p38 MAPK signaling pathway in pro-inflammatory microglia is reverted by miR-467f and miR-466q. Images (a) and quantification (b) of immunofluorescence analysis indicated that transfection with miR-467f and miR-466q, alone or combined (N9+Mix+LPS), reverted the over-phosphorylation of p38 in LPS-activated N9 cells to that of non-activated N9 cells. \#\#\#P $<0.0001$, untreated (N9) vs LPSactivated N9 cells (N9+LPS) or LPS-activated N9 transfected with the negative control (N9+Cneg+LPS); 
***P $<0.0001$, N9+LPS vs N9+LPS transfected with specific miRNA (N9+miRNA+LPS or N9+Mix+LPS). Data are presented as mean \pm SEM of 3 experiments. 